\title{
A LUDICIDADE NA ALFABETIZAÇÃo MATEMÁTICA NO ÂMBITO DA EDUCAÇÃO INFANTIL
}

\section{THE PLAYFULNESS OF MATHEMATICAL LITERACY IN THE FIELD OF EARLY CHILDHOOD EDUCATION}

Eliete da Silva Cambraia ${ }^{1}$

Nilce Léa Lobato ${ }^{2}$

\author{
Rômulo Pereira Nascimento ${ }^{3}$
}

\begin{abstract}
RESUMO: O estudo tem como tema investigar as etapas do desenvolvimento infantil no processo de alfabetização e conhecimento matemático com o objetivo de identificar como a criança é vista pelo professor dentro da didática pedagógica na alfabetização matemática ${ }^{4}$ através de lúdico. A luz dos teóricos Piaget (2007), Vigostsky (2000), Pais (2006), será analisado o uso de jogos e brincadeiras na educação infantil, com base nas pesquisas de Kishimoto (2000), Brougére (2003) entre outros autores. Por meio da pesquisa de campo traremos resultados para o aprimoramento contínuo e com base no estudo qualitativo abordaremos a atividade lúdica como instrumento facilitador na sala de aula que irá permear uma educação de qualidade valorizando o sujeito em distintos campos do saber.
\end{abstract}

PALAVRAS-CHAVE: conhecimento matemático, aprendizagem, desenvolvimento infantil.

ABSTRACT: The purpose of this study is to investigate the stages of child development in the process of literacy and mathematical knowledge in order to identify how the child is seen by the teacher within the pedagogical didactics in mathematical literacy through games. In light of the theorists Piaget (2007), Vigostsky (2000), Parents (2006), will be analyzing the use of games in early childhood education, based on the researches of Kishimoto (2000), Brougére (2003) among other authors. Through the field research we will bring results for continuous improvement and based on the qualitative study. Also, from this study, we will address

\footnotetext{
${ }^{1}$ Licencianda em Pedagogia Universidade Cruzeiro do Sul. elietecambraia@gmail.com

${ }^{2}$ Mestre em Politicas Sociais: Universidade Cruzeiro do Sul; Docente do curso de Pedagogia da Universidade Cruzeiro do Sul.nilce.lobato@hotmail.com

${ }^{3}$ Doutor em Educação: História, politica, sociedade pela Pontíficia Universidade Católica de São Paulo.

Professor Titular da Universidade Cruzeiro do Sul.romulo.nascimento@uol.com.br
}

Tangram - Revista de Educação Matemática, Dourados - MS - v.1, n. 2, pp. 76 - 91 (2018) ISSN: 2595-0967 
playfulness as a facilitator in the classroom that will flow onto a quality education valuing the subject in diferente fields of knowledge.

KEYWORDS: mathematical knowledge, learning, child development.

\section{INTRODUÇÃO}

Este projeto de pesquisa faz parte do Grupo de Pesquisa: Práticas Pedagógicas na Formação de Professores, onde venho pesquisando juntamente com o grupo de professores e alunos as práticas docentes e elaborando materiais, estratégias e jogos pedagógicos. Esse grupo tem como objetivo principal a formação de professores, e a efetivação da profissão docente baseada na ação e na prática educativa. A proposta do Projeto de Iniciação Científica, tem a finalidade de estudar, redescobrir as dificuldades e a debilidade na área do conhecimento matemático a partir da primeira infância considerando as etapas do desenvolvimento infantil. Outro fator de grande relevância que nos fez pensar sobre esse estudo foi a necessidade de conscientizar pais e professores a importância da bagagem que a sociedade impõe sobre a criança, desvalorizando suas falas e sufocando suas vivencias. Bicudo (1987), afirma que "no ensino tradicional da matemática, o ouvir o aluno não tem sido, em geral, valorizado; no entanto, é preciso saber ouvir e não apenas falar, pois ouvir faz parte da comunicação”. Cabe ao professor interrogar o aluno acerca da realidade em que ele vive, para que haja uma interação entre a ação pedagógica e a criança.

De acordo com BICUDO, (1987, p.31) "para que surja a educação Matemática em que haja a comunicação entre professor e aluno é preciso que se substitua o monologo tradicional de nossas salas de aula para o diálogo". Sabemos que desde o seu nascimento, as crianças estão expostas e são submetidas a distintas atividades lúdicas em qualquer área do conhecimento, neste sentido, enquanto sujeito vale destacar a área do conhecimento matemática aqui contextualizada.

Podemos verificar o que afirma Piaget (2007), a criança aprende por meio de assimilação e acomodação que são instrumentos pedagógicos para a construção do conhecimento, ou seja, estruturas da inteligência que lhe permitem uma organização progressiva sobre o ato de conhecer.

Tangram - Revista de Educação Matemática, Dourados - MS - v.1, n. 2, pp. 76 - 91 (2018) 
Levando em conta, então, esta interação fundamental entre fatores internos e externos, toda conduta é uma assimilação do dado a esquemas anteriores (assimilação a esquemas hereditários em graus diversos de profundidade) e toda conduta é, ao mesmo tempo, acomodação destes esquemas a situação atual. Daí resulta que a teoria do desenvolvimento apela, necessariamente, para a noção de equilíbrio entre os fatores internos e externos ou, mais em geral, entre a assimilação e a acomodação (PIAGET, 2011, p.89).

A criança é um sujeito histórico social que traz consigo conhecimentos prévios já adquiridos e experiências relacionadas ao meio em que vivem que merecem ser valorizadas.

Conforme Vigotsky (2000), a criança, ao aprender, desenvolve-se e, ao se desenvolver ela aprende, ou seja, ele defende a ideia de que a interação com o meio é extremamente indissociável ao aprendizado, pois ambos estão intimamente entrelaçados pelas experiências vivenciadas pelo indivíduo.

Nota se que, a educação infantil é uma fase de extrema importância na vida escolar das crianças e do sujeito em formação, pois é a partir deste contato inicial que eles irão começar a construir suas hipóteses para a longa jornada da vida.

Segundo Alarcão (2005), professores reflexivos constroem uma escola reflexiva, norteada por este princípio básico é que buscamos despragmatizar a existência dos obstáculos didáticos que ocorrem particularmente no nível de aprendizagem no âmbito escolar e na formação especializada docente.

Compreende-se que o professor reflexivo é mediador do conhecimento não detentor do saber, pois de acordo com Freire (1996, p.27) "ensinar não é transferir conhecimentos, mas criar as possibilidades para a sua própria produção ou a sua construção". Desta forma, ressalta-se a ideia de que o professor deve ser um constante pesquisador, ou seja, ao mesmo tempo em que ensina não deixa de ser aprendiz e encontra-se sempre disponível para ampliar as distintas formas de uma aprendizagem lúdica cada vez mais prazerosa.

A ludicidade é uma forma didática pedagógica estudada por muitos pesquisadores que visam aprimorar o ato das descobertas realizadas pelas crianças através de suas interações e trocas de experiência. A esse respeito Dallabona; Mendes (2004) diz que:

O lúdico permite um desenvolvimento global e uma visão de mundo mais real. Por meio das descobertas e da criatividade, a criança pode se expressar, analisar, criticar e Tangram - Revista de Educação Matemática, Dourados - MS - v.1, n. 2, pp. 76 - 91 (2018) 
transformar a realidade. Se bem aplicada e compreendida, a educação lúdica poderá contribuir para a melhoria do ensino, quer na qualificação ou formação crítica do educando, quer para 21 redefinir valores e para melhorar o relacionamento das pessoas na sociedade (DALLABONA; MENDES, 2004, p. 107).

Levando em consideração que o conhecimento é processual e adquirido de acordo com o tempo individual de cada vale ressaltar os cuidados necessários que o professor terá neste contexto.

\begin{abstract}
Faz-se necessário respeitar o tempo de a criança ser criança, sua maneira absolutamente original de ser e estar no mundo, de vivê-lo, de conhecê-lo tudo simultaneamente. É preciso quebrar alguns paradigmas que foram sendo criados. Brinquedo não é só um presente, um agrado que se faz a criança: é investimento em crianças sadias do ponto de vista psicossocial. Ele é a estrada que a criança percorre para chegar ao coração das coisas, para desvelar os segredos que lhe esconde um olhar surpreso ou acolhedor, para desfazer temores, explorando o desconhecido. (DALLABONA E MENDES, 2004, p. 109).
\end{abstract}

Estudaremos à luz de estudos teóricos autores como: Piaget. Vigotsky, Luiz Carlos Pais, Paulo Freire entre outros autores e, de acordo com a Lei de Diretrizes e Bases da Educação Nacional.9.394/96 onde afirma que “ A Educação Infantil, primeira etapa da educação básica, tem como finalidade o desenvolvimento integral da criança até os seis anos de idade, em seus aspectos físico, psicológico, intelectual e social, complementando a ação da família e da comunidade (BRASIL, 1996, art., 29). Consolidando essa orientação o professor tem como por dever estimular a criança através de brincadeiras visando seu pleno desenvolvimento cognitivo, físico, psicológico, intelectual e social.

A Matemática está presente na nossa vida desde o nosso nascimento, quase tudo no nosso dia-a-dia envolve números, medidas, figuras geométricas e outros conceitos intrínsecos a essa ciência. Antes mesmo de dar início a o período escolar, as crianças já têm relação com elementos matemáticos no seu cotidiano, aprendendo sem sequer compreender. Já na escola, a Matemática aparece, por exemplo, quando dividem o lanche com os amigos ou respondem a sua idade com os dedos. Moura et al (2010) afirmam que, "ainda que o sujeito possa se apropriar dos mais diversos elementos da cultura de maneira não proposital, [...], é no processo da educação escolar que ocorre a intencionalidade social. A partir do exposto a prática da educação infantil possibilita circunstâncias que leva à criança observar, pensar, interpretar, buscar e encontrar com elucidações ou dificuldade em diferentes situações

Tangram - Revista de Educação Matemática, Dourados - MS - v.1, n. 2, pp. 76 - 91 (2018) 
Uma das teorias de Piaget (1976) é ensinar que a Matemática na educação infantil ultrapassa o ato de ensinar a contar.

\begin{abstract}
Os fundamentos para o desenvolvimento matemático das crianças estabelecem-se nos primeiros anos. A aprendizagem matemática constrói-se através da curiosidade e do entusiasmo das crianças e cresce naturalmente a partir das suas experiências (...) A vivência de experiências matemáticas adequadas desafia as crianças a explorarem ideias relacionadas com padrões, formas, número e espaço duma forma cada vez mais sofisticada (PIAGET, 1976, p.73).
\end{abstract}

Pode se destacar o elaborado Referencial Curricular Nacional para Educação infantil (RCNEI) publicado pelo ministério da educação em 1998, que é misto de várias sugestões e orientações didáticas, para os docentes e demais profissionais da educação infantil. Este documento transporta orientação educacional que delimita os desígnios e teores da educação infantil, organizado em dois âmbitos de experiências designados formação pessoal e social e o conhecimento de mundo. Neste sentido o Referencial Curricular Nacional para Educação infantil (BRASIL, 1998, p.46) afirma que, "preciso ressaltar que esta organização possui um caráter instrumental e didático, devendo os professores ter consciência, em sua prática educativa".

É oportuno lembrar que:

Diversas ações intervêm na construção dos conhecimentos matemáticos, como recitar a seu modo a sequência numérica, fazer comparações entre quantidades e entre notações numéricas e localizar-se espacialmente. Essas ações ocorrem fundamentalmente no convívio social e no contato das crianças com histórias, contos, músicas, jogos, brincadeira. (RCNEI, 1998, p.200).

O desafio didático é articular estratégia que contribuam na formação desses saberes cotidiano para o saber escolar e enxergar a matemática como ciência.

Neste contexto PAIS (2006), ressalta várias dimensões sobre as didáticas quando ele diz que é recomendável haver um contrato didático entre o aluno e o professor, onde em suas cláusulas o professor só pode problematizar até onde o aluno consegue compreender, e para isso o educador devera se planejar e conhecer os alunos, pois a partir do momento que ele ensina algo que vai além do que o aluno consegue compreender há uma quebra de contrato.

Tal fato deve ser levando em consideração a vivência do aluno diante do que é proposto pelo professor, parafraseando Smole (2000), onde afirma que, "a escola infantil o trabalho com Tangram - Revista de Educação Matemática, Dourados - MS - v.1, n. 2, pp. 76 - 91 (2018) 
a matemática permanece subjacente, escondido sob uma concepção de treinar as crianças a darem respostas corretas, ao invés de fazê-las compreender a natureza das ações matemáticas". É oportuno lembrar que, o papel do professor pesquisador é mediar conhecimento, impulsionando o alunado a pensar, criar hipótese afim que alcance a compreensão do conteúdo.

O professor mediador deve trabalhar para detectar essas lacunas na compreensão do aluno, explicar o porquê se faz, como se faz, onde se faz, e onde será utilizada de forma a motivar o aluno na aprendizagem, a fim de desenvolver o habito de pensar de forma autônoma. Assim, o professor pesquisador buscara se inteirar de conhecimentos pedagógicos que propicie a autonomia do aluno, contribuindo para o crescimento e tendo a consciência que é necessário planejamento, condições de aprendizagem através do espaço, " é apropriado planejar situações que favoreça a expansão do significado do conceito para o aluno visto que, entre todos os conceitos os que desperta interesse do aluno são aqueles que se encontram localizados em um quadro de significado por ele perceptível" (PAIS, 2006, p. 58).

Esse conhecimento da matemática, a criança se apropria através do meio em que está inserida, porém, interpretado pelos pais que muitas vezes alfabetizados pelo ensino tradicional, transmite para o filho a ideia que a matemática é complicada e difícil, e quando este aluno chega na educação infantil, traz com ele essa ideia que não conseguirá resolver questões.

Ao analisar os temas desses livros, "A eterna dificuldade com a matemática" (Bissigo, 1998, p. 4), "a histórica dificuldade enfrentada por professores e estudantes no ensino da ciência dos números" (Ib.), "o mito de que a matemática é disciplina difícil" (Junqueira, 1998, p. 9), "o mito de que só aprende matemática quem é inteligente" (Ochôa, 1997, p. 12) e "o mito de que matemática é difícil e feita para alguns iluminados" (Greco, 1998, p. 6) só elucida a ideia da dificuldade que o aluno encontrara na sala de aula.? A ideia que a matemática é um "bicho de sete cabeças" está internalizada no consciente dos pais e alguns docentes que através de suas práticas e costume empírico transmite ao alunado que esse conceito é real. Ao analisarmos KISHIMOTO (2000), observa-se que a maneira que a professora apresenta a matemática para o aluno está ligada a essa rejeição ou aceitação levando em conta o que foi lido, como a literatura atual tem discutido a alfabetização matemática no âmbito da educação infantil.

Assim nossos objetivos neste trabalho são:

Tangram - Revista de Educação Matemática, Dourados - MS - v.1, n. 2, pp. 76 - 91 (2018) 
- Identificar como o aluno é visto pelo professor dentro da didática pedagógica na alfabetização matemática através do lúdico..

- Investigar o uso do jogo, brinquedos e brincadeira na educação infantil.

- Aperfeiçoar o conhecimento matemático das crianças na educação infantil através do lúdico.

\section{METODOLOGIA}

O que impulsionou a realização deste projeto de pesquisa foi a inquietude contida no processo de formação do sujeito frente a construção de suas aprendizagens. O processo de construção e elaboração da presente pesquisa, será de caráter qualitativo, de acordo com Oliveira, (1998, p 117)

[...] de abordagem qualitativa, pois possuem a facilidade de poder descrever a complexidade de uma determinada hipótese ou problema, analisar a interação de certas variáveis, compreender e classificar processos dinâmicos experimentados por grupos sociais, apresentar contribuições no processo de mudança, criação ou formação de opiniões de determinado grupo e permitir, em maior grau de profundidade, a interpretação das particularidades dos comportamentos ou atitude dos indivíduos. (OLIVEIRA, 1998, p.117).

E Através de levantamento bibliográfico sobre a temática, encontrará respaldo que fundamente teses já colocadas e ampliará o conhecimento do pesquisador em ação. Segundo Marconi e Lakatos, podemos afirmar que;

\footnotetext{
“A pesquisa bibliográfica: Trata-se do levantamento de toda a bibliografia já publicada em forma de livros, revistas, publicações avulsas em imprensa escrita [documentos eletrônicos]. Sua finalidade é colocar o pesquisador em contato direto com tudo aquilo que foi escrito sobre determinado assunto, com o objetivo de permitir ao cientista o reforço paralelo na análise de suas pesquisas ou manipulação de suas informações. " (MARCONI E LAKATOS, 2001, p. 43-44).
}

Para alcançar os objetivos propostos neste trabalho será efetuada uma entrevista semiestruturada e um questionário podendo conter perguntas abertas e fechadas, seguindo o Manual de Pesquisa Qualitativa (2014) e Marconi e Lakatos (2003) no qual afirma que na entrevista semiestruturada,

Tangram - Revista de Educação Matemática, Dourados - MS - v.1, n. 2, pp. 76 - 91 (2018) 
“o roteiro pode possuir até perguntas fechadas, geralmente de identificação ou classificação, mas possui principalmente perguntas abertas, dando ao entrevistado a possibilidade de falar mais livremente sobre o tema proposto". (MARCONI E LAKATOS, 2001, p. 43-44).

E nesta entrevista será aplicado um questionário que este confirmará a fala da entrevista, possibilitando maior compreensão das respostas que não ficaram evidentes, ainda de acordo com Marconi e Lakatos (2003, p. 201) definem questionário como sendo "um instrumento de coleta de dados, constituído por uma série ordenada de perguntas, que devem ser respondidas por escrito e sem a presença do entrevistador" Usaremos esses meios para ter como base o fundamento teórico do professor em sala de aula, em seguida será feito também visitas de observação definida por MARCONI E LAKATOS como:

É uma técnica de coleta de dados para conseguir informações e utiliza os sentidos na obtenção de determinados aspectos da realidade. Não consiste apenas em ver e ouvir, mas também em examinar fatos ou fenômenos que se desejam estudar. (MARCONI E LAKATOS, 2003, p. 190)

Rumo a resposta dos objetivos proposto será feita também uma sondagem diagnóstica, afirmando e confirmando os estudos de (FERREIRO E TEBEROSKY (1981 p, 130) no qual afirma que a sondagem "não é uma avaliação, é uma observação das características do pensamento dos alunos com o objetivo de verificar como aluno pensa para poder planejar as intervenções da professora". E também uma brincadeira de faz de conta que segundo KISHIMOTO (2011) é a brincadeira que estimula o imaginário, aguça a imaginação, estimulando a criatividade do aluno, e por último uma pesquisa-ação, no qual Thiollent (2007) assegura que essa ação é "uma contribuição da pesquisa na solução do problema e também um conhecimento gerado a partir da solução", onde traremos resultados relevantes para o conhecimento da alfabetização matemática.

No primeiro momento, serão contactado duas escolas públicas e duas escola particulares indo de encontro a Oliveira (2009) no qual afirma que "a principal justificativa para utilizar essa metodologia é que ela permite construir intervalos de confiança e realizar inferência estatística" ou seja, poderá ocorrer intervalos entre uma escola e outra e os resultados é apenas uma amostra coletada onde será analisado um todo, buscando resultados imparciais possibilitando a compreensão ampla da sociedade.

Tangram - Revista de Educação Matemática, Dourados - MS - v.1, n. 2, pp. 76 - 91 (2018) 
Detalharemos a seguir o passo a passo da aplicação dos meios escolhidos para que os objetivos sejam alcançados. Para atingir o primeiro objetivo proposto neste projeto será colhido resultados através de entrevista semiestruturadas e questionário aplicada ao professor no intuito de buscar entender qual o olhar do professor ao aluno e como esse olhar interfere na didática lúdica em sala de aula, em seguida serão realizadas visitas de observação para averiguar se a concepção da criança dita pela professora na entrevista está de acordo com suas práticas. E por intermédio das respostas será realizado uma pesquisa-ação no qual traremos resultados que apontara a aproximação das teorias aqui citadas a das práticas da rotina diária na educação infantil.

No segundo momento, em caráter de pesquisa de campo e em nível de conhecimento, alcançaremos o segundo objetivo da pesquisa, investigando através de observações da rotina no qual será elaborado um roteiro de observação que contemple objetivos propostos da pesquisa, o roteiro direcionará o olhar para que, por meio da observação obtenhamos elementos suficientes para relacionar com os teóricos no momento da análise dos dados. Poderemos observar o espaço, a organização da sala, as ações das crianças, dissertaremos informações que foram colhida da prática docente alfabetizadora do conhecimento matemático com crianças da educação Infantil na idade de cinco a seis anos.

Para nos aproximar do terceiro objetivo da nossa pesquisa, além de observar os procedimentos da professora regente de sala, e juntamente com a mesma será realizada uma sondagem onde será identificado o estágio do conhecimento do aluno, com o intuito de saber se eles já compreendem o sistema numérico ${ }^{5}$, considerando o que LERNER, D. e SADOVSKY (1996) "afirma que o aluno quer saber cada vez mais cedo possível com funciona e para que serve e quando se usa e não se interessam pela compreensão e sim a sua utilidade ", baseado nisso entende-se a necessidade de criar situações que possibilite a utilidade dos números centrados na comparação que estão vinculadas a ordenação do sistema numérico, proporcionando um real significado ao número. Reconhecendo essa verdade e ainda de acordo com LERNER, D. e SADOVSKY (1996) no qual aponta exemplos para melhorar a compreensão dessas relações como " uma loja de balas que venda diferentes qualidades, e pedir

\footnotetext{
${ }^{5}$ Sistema Numéricos de acordo LERNER, D. e SADOVSKY (1996), são ideias elaboradas sobre números, formulação de problemas e conflitos existentes.

Tangram - Revista de Educação Matemática, Dourados - MS - v.1, n. 2, pp. 76 - 91 (2018)
} 
as crianças que decidam qual o preço, permitindo fazer comparações em conjunto, orientadas por uma lógica"

\begin{abstract}
Alguns exemplos podem melhorar o entendimento dessas relações, são elas: simulação de uma loja para vender balas, em pacotes de diferentes quantidades. Ao sugerir que as crianças decidam qual o preço de cada tipo de pacote, estarão fazendo comparações em conjunto com os colegas, notações, comparam as divergências, argumentam e discutem as ideias, orientadas por uma lógica. (LERNER, D. e SADOVSKY (1996).
\end{abstract}

E é através dessa perspectiva, que alcançaremos o terceiro objetivo da proposta de pesquisa onde será apresentado a brincadeira de faz de conta possibilitando e fixando a aprendizagem matemática através do lúdico, e desenvolvendo no aluno o conhecimento do sistema de numeração decimal, adição e subtração; conceito de grande e pequeno; paladar azedo e doce; quantidade muito e pouco, dentro e fora; formas e cores das frutas; associação de número quantidade; conceito de textura, duro ou mole, considerando que na educação infantil através dos Referencias Curriculares da Educação Infantil (1998, p. 202) orienta que a criança inserida na educação infantil deverá "reconhecer e valorizar os números, as operações numéricas, as contagens orais e as noções espaciais como ferramentas necessárias no seu cotidiano".

No quarto momento, propor com o aval da professora, uma receita de salada de frutas, dado que nos Referenciais Curriculares da educação infantil (1998 p. 202) orienta trabalhar em situações que estejam presentes no cotidiano das crianças, e algumas noções matemáticas, como contagem, relações espaciais etc," disponibilizando frutas em cestas individuais separadas de acordo sua espécie e de tamanho, propor aos alunos que cada dê o valor para as frutas de acordo com o que acredita que vale dependendo o tamanho, ex: maça grande dois reais, maçã pequena um real, em seguida distribuir uma quantidade igual de "cédulas de dinheiro de brincadeira", e convida-los a ir às compras. Em seguida dispor aos alunos um avental e uma touca, feito de TNT (tecido não tecido) leva-los a imaginar que estão em uma cozinha e cada um criará a receita de acordo com o que sabe e conhece, logo após cortar as frutas com faca plástica e sem ponta, e no final da receita todos experimentar a criação propiciando a autonomia o bem estar e conduzindo a aprendizagem significativa da importância dos números.

Tangram - Revista de Educação Matemática, Dourados - MS - v.1, n. 2, pp. 76 - 91 (2018) 
Buscando encontrar e frisar a importância desse instrumento de aprendizagem como fonte inesgotável de possibilidades, espera-se que as devolutivas pelo presente estudo busquem subsidiar uma prática transformadora dos profissionais atuantes na tentativa eficaz de contextualizar uma realidade cada vez mais gradativa e significativa ao interesse de aprendizagem e conhecimento das crianças. Contribuindo com uma prática mais centrada no conhecimento contextualizado trazendo um significado para a vida.

\section{REVISÃO DE LITERATURA}

Desde os primórdios dos tempos os conhecimentos matemáticos fazem parte da vida e da formação humana. A partir da inquietude por esta construção tão significativa estudaremos a linha teórica que sustentará bases reais e consolidadas sobre as etapas deste desenvolvimento.

Diante de tantas contrariedades sobre o ensino matemática, a partir dos Referências Curriculares da Educação Nacional, buscou através de estudos minimizar os obstáculos encontrados na aprendizagem dessa ciência, encontrando na ludicidade, um instrumento que gera conhecimento ao aluno, proporcionando o contínuo desenvolvimento.

Mas afinal, o que significa ludicidade? Em nenhuma outra língua encontra-se o significado real da ludicidade, para compreender sua manifestação vamos estudar o conceito da palavra. De acordo com Brougère (2003) e Huizinga (2008) “ a expressão oral sobre os inúmeros conceitos da palavra "jogo" associa ao conceito de ludicidade, ao analisarmos a origem semântica da palavra, descobrimos que vem do latim LUDUS, que significa jogo, exercício ou imitação". Estudaremos a ludicidade de acordo com KISHIMOTO (2000), onde afirmam que "não se pode confundir jogo com brinquedo e brincadeira, os quais se relacionam diretamente com a criança".

Sendo assim, jogo em si, não deve exigir sempre resultado positivo da criança, ele tem que causar prazer, assim como o ato de brincar, se a criança se sente desconfortável com as regras, com sinais de cansaço e tedio, esse jogo não está alcançando aprendizagem pedagógica. São várias as formas de interpretar o jogo em sua essência, pois ele tem vertentes que são decodificadas de acordo com o contexto social que a criança está inserida. Vale aqui ressaltar que:

Tangram - Revista de Educação Matemática, Dourados - MS - v.1, n. 2, pp. 76 - 91 (2018) 
Brinquedo é outro termo indispensável para compreender esse campo. Diferindo do jogo, o brinquedo supõe uma relação com a criança e uma abertura, uma indeterminação quanto ao uso, ou seja, a ausência de um sistema de regras que organizam sua utilização. O brinquedo está em relação direta com uma imagem que se evoca de um aspecto da realidade e que o jogador pode manipular. Ao contrário, jogos, como xadrez, construção, implicam de modo explícito ou implícito, o desempenho de certas habilidades definidas por uma estrutura preexistente no próprio objeto e suas regras. (KISHIMOTO, 2000 p.108).

O brinquedo é diferente do jogo, pois é um objeto que a criança atribui sentido a ele colocando a criança frente a imitações ao que existe em seu cotidiano podendo dispor de sua realidade e transferir para o objeto e manipula-lo. O brinquedo propõe um mundo imaginário, onde o adulto pode se apropriar para o ensino lúdico mediando o conhecimento do alunado.

De acordo com KISHIMOTO (2000), "brinquedo" não pode ser reduzido à pluralidade de sentidos do jogo, pois conota criança e tem uma dimensão material, cultural e técnica. Enquanto objeto, é sempre suporte de brincadeira $\mathrm{O}$ professor ao se apoderar do brinquedo é levado a antigas memorias de infância e estimula o imaginário infantil.

O último entre eles e não mais importante é a brincadeira, onde a criança se ocupa do jogo e do brinquedo para mergulhar na ação lúdica. Quando a criança brinca ela se distancia do real e entra no mundo imaginário. Entre outras brincadeiras, a tradicional infantil, tem grande destaque pois evidencia a cultura, incorpora o entendimento popular.

Através da brincadeira que a criança resgata a cultura infantil das gerações anteriores mantendo a tradição e a universalização do brincar, “ muitas brincadeiras preservam sua estrutura inicial, outras modificam-se, recebendo novos conteúdos” KISHIMOTO (2011, p.43), mas sempre mantém a essência da brincadeira, mesmo mudando uma palavra ou outra de acordo com a cultura do local.

Conforme apontado por KISHIMOTO (2011 p.43) "a brincadeira de faz de conta é também conhecida como simbólica, como representação de papeis ou sócio-dramática, uma vez que deixa evidente a presença da situação imaginaria”. A brincadeira simbólica é espontânea, e surge junto quando a oralidade é alcançada, a criança começa a dar novos significados aos objetos, proporcionando bagagem vivenciada e ampliando seu repertorio de palavras e novas experiências.

Tangram - Revista de Educação Matemática, Dourados - MS - v.1, n. 2, pp. 76 - 91 (2018) 
Dessa forma KISHIMOTO (2011, pg. 44) afirma que, “A brincadeira de construção, são consideradas de grande importância para enriquecer a experiência sensorial, estimular a criatividade e desenvolver habilidades da criança" quando a criança está interagindo com os objetos que possibilita a construção de novos objetos, além de expressar o seu imaginário, ela está manifestando seu lado afetivo e intelectual. Ao analisarmos o exposto pode-se afirmar que, o jogo, brinquedos e brincadeira,

\footnotetext{
Deve ser usado na educação matemática obedecendo a certos níveis de conhecimento dos alunos tidos como mais ou menos fixo. O material a ser distribuído para os alunos deve ter estrutura tal que que permita um salto na compreensão dos conceitos matemáticos (KISHIMOTO, 2011, p.87).
}

Tais concepções de aprendizagens, são significativos como parte do desempenho pedagógicas, pois são elementos instigadores do desenvolvimento, considerando que o jogo é um instrumento de aprendizagem que promove a execução de um pensamento que sustenta uma nova estrutura. O material a ser disponibilizado pelos alunos deve ser composto de significados que permita que o aluno alavanque a compreensão dos conceitos matemáticos.

\section{ALGUMAS CONSIDERAÇÕES}

Consideramos que este artigo tenha contribuído seu objetivo de aprimorar o ato das descobertas realizadas pelas crianças através das interações e permuta de bagagem. Defendo a ideia que o lúdico contribui no processo de alfabetização e conhecimento matemático porque permite a compreensão evolutiva quanto ao conhecimento de mundo mais real. Através da prática da ludicidade a criança analisa e transforma sua realidade proporcionando o desenvolvimento e favorecendo a compreensão.

Portanto, asseguramos a magnitude desta ferramenta de aprendizagem como um manancial interminável de saberes. Faz necessário compreender que os resultados contribuem para uma ação transformadora dos educadores da educação infantil no tentamento capaz de contextualizar através do cotidiano das crianças de uma maneira prazerosa, gradual e significativa.

Tangram - Revista de Educação Matemática, Dourados - MS - v.1, n. 2, pp. 76 - 91 (2018) 
Em síntese, é necessário conhecer o interesse de aprendizagem e conhecimento matemático impulsionando um maior significado para a vida dos alunos incentivando-os a serem autônomos e mediando a busca pelo conhecimento pleno. Questões como a metodologia, as atividades lúdicas farão com que o aluno busque a solução do problema proposto havendo uma maior interação com seus colegas, além de dinâmico, faz com que os alunos sintam maior prazer em aprender, pois eles se identificam, ajudam a desenvolver o interesse de cada um tornando-os capazes de compreender com clareza as atividades. Assim, deixando de existir diferenças entre alunos em relação ao aprendizado. Todos têm a capacidade de aprender, de uma maneira totalmente lúdica e interessante para sua idade.

\section{REFERÊNCIAS}

ALARCÃO, Professores reflexivos em uma escola reflexiva. São Paulo: Cortez, 2005. BRASIL. Ministério da Educação e do Desporto. Lei de Diretrizes e Bases da Educação Nacional. Lei n. 9394, de 20 de dezembro de 1996.

BRASIL, Ministério da Educação. Ensino Fundamental de nove anos: Orientações para a inclusão da criança de seis anos de idade. Brasília, DF: MEC, 2007.

Brasil. Ministério da Educação e do Desporto. Secretaria de Educação Fundamental. Referencial curricular nacional para a educação infantil / Ministério da Educação e do Desporto, Secretaria de Educação Fundamental. — Brasília: MEC/SEF, 1998. 3v.: il.

BISSIGO, Luís. A eterna dificuldade com a matemática. Jornal do vestibular, Porto Alegre, p. 4, 21 jan. 1998.

BICUDO, M. A. V. . INTRODUCAO. In: BICUDO, M.A.V. (ORG). (Org.). Educação Matemática. SAO PAULO: MORAES, 1987, v. , p. 9-35

DALLABONA, S.R,. MENDES, S.M.S. O Lúdico na Educação Infantil: Jogar, Brincar, uma forma de Educar. Revista de divulgação técnico-científica do ICPG, v.1, n. 4, p.107-112, mar./2004 DICIONÁRIO UNIVERSAL DA LÍNGUA PORTUGUESA. On-line

DANYLUK, O. S. Um estudo sobre o significado da alfabetização matemática. Rio Claro (SP): IGCE-UNESP, 1988. Dissertação de Mestrado.

Tangram - Revista de Educação Matemática, Dourados - MS - v.1, n. 2, pp. 76 - 91 (2018) 
FREIRE, Paulo. Pedagogia da Autonomia. Saberes necessários à prática educativa. São Paulo: Paz e Terra, 1996. 148p.

FERREIRO, Emília e TEBEROSKY, Ana. Psicogênese da língua escrita. Porto Alegre: Artes Médicas, 1996. FERREIRO, Emília. Reflexões sobre alfabetização. São Paulo: Cortez, 1981. GRECO, Alessandro. Como tornar a matemática fascinante. Gazeta Mercantil, São Paulo, p. 6, 4 e 5 de abr. 1998.

HUIZINGA, J. Homo Ludens: o jogo como elemento da cultura. $4^{\mathrm{a}}$ ed. Tradução João Paulo Monteiro. São Paulo: Perspectiva, 2000.

JUNQUEIRA, Eduardo. Garotão nota dez. Veja, São Paulo: Ed. Abril, p. 9-13, ago. 1998.

KISHIMOTO, T. M. (org.). Jogos, brinquedos, brincadeiras e educação. $4^{\mathrm{a}}$ ed. São Paulo: Cortez, 2000.

LERNER, D. e SADOVSKY, P. O sistema de numeração: um problema didático. In: PARRA, Cecília; SAIZ Irmã; [et al] (Org.). Didática da Matemática: Reflexões Psicopedagógicas. Tradução por Juan Acuña Llorens. Porto Alegre: Artes Médicas, 1996. p. 73-155

MARCONI, M. de A.; LAKATOS, E. M. Metodologia do Trabalho Científico. $5^{\circ}$ ed. rev. ampl. São Paulo: Atlas, 2001.

MARCONI, M. de A.; LAKATOS, E. M. Fundamentos de metodologia científica. 5. ed. São Paulo: Atlas, 2003

Ministério da Educação e do Desporto. Secretaria de Educação Fundamental. Coordenação Geral da Educação Infantil. Referencial Curricular Nacional para a Educação Infantil, volume 1. Brasília, 1998a.

MOURA, M. et al. A atividade orientadora de ensino como unidade entre ensino $e$ aprendizagem. In: MOURA, Manoel Oriosvaldo de (Coord.). A atividade pedagógica na teoria histórico-cultural. Brasília. Líber, 2010.

OCHÔA, Valéria. Quem tem medo da matemática? Extra Classe, Porto Alegre, p. 11- 14, abr. 1997.

OLIVEIRA, P. R.; BELlUZZO, W.; PAZELLO, E. T. Public-private sector differentials in Brazilian education: A counterfactual decomposition approach. In: ENCONTRO BRASILEIRO DE ECONOMETRIA, 31., 2009, Foz do Iguaçu. Anais... Foz do Iguaçu, 2009. PAIS, Luis Carlos. Ensinar e aprender Matemática. Belo Horizonte: Autêntica, 2006. 152 p. ISBN: 85-7526-221-.

Tangram - Revista de Educação Matemática, Dourados - MS - v.1, n. 2, pp. 76 - 91 (2018) 
PARÂMETROS CURRICULARES NACIONAIS: matemática/Ministério da Educação. Secretaria da Educação fundamental. - 3. ed. Brasília: A Secretaria, 2001. Acessado dia 22/03/2018

PIAGET, Jean. Epistemologia Genética. Tradução: Álvaro Cabral. $3^{\mathrm{a}}$ ed. Martins Fontes: São Paulo, 2007.

PIAGET, J. Psicologia e Pedagogia. Rio de Janeiro. Forense Universitária, 1976

SMOLE. K. C. S. A matemática na educação infantil: a teoria das inteligências múltiplas na prática escolar. Porto Alegre: Artmed, 2000.

THIOLLENT, Michel. Metodologia de pesquisa-ação. 15 ed. São Paulo: Cortez, 2007. A construção do pensamento e da linguagem

VIGOTSKI, L.S.. São Paulo: Martins Fontes, 2000.

Enviado: 22/04/2018

Aceito:06/06/2018

Tangram - Revista de Educação Matemática, Dourados - MS - v.1, n. 2, pp. 76 - 91 (2018) 